\title{
Treatment of hepatitis $C$ virus infection with direct-acting antiviral agent-based regimens in Iranian patients with hereditary bleeding disorders
}

\author{
Heidar Sharafi', Bita Behnava', Alireza Azizi-saraji², Ali Namvar², Ali Anvar², Shima Salimii and \\ Seyed Moayed Alavian ${ }^{1,3^{*}}$
}

\begin{abstract}
Background: Chronic hepatitis $\mathrm{C}(\mathrm{CHC})$ is one of the most important comorbidities in patients with hereditary bleeding disorders (HBD). The present study aimed at evaluating the effectiveness of direct-acting antiviral agent (DAA)-based interferon-free HCV antiviral regimens in patients with HBD.
\end{abstract}

Patients and methods: The present study was performed on the patients with HBD and CHC between 2015 and 2019. Sofosbuvir-based interferon-free regimens with or without ribavirin were prescribed to treat HCV infection. The main endpoint of the study was to determine the sustained virologic response (SVR), assessed 12 weeks after the completion of treatment.

Results: A total of 147 patients with a mean age of 41.1 years were enrolled in the study; $4.1 \%$ of them were coinfected with HIV, $25.2 \%$ had cirrhosis, and $76.9 \%$ of them were diagnosed with hemophilia A. HCV genotype-1 includes the largest number (68.1\%) of patients. $46.3 \%$ of patients were treatment-naïve and others had a treatment history with interferon-based regimens. Out of 147 patients, 15 patients were lost to follow-up during treatment or for SVR evaluation or discontinued treatment. 132 subjects completed treatment and were evaluated for SVR, 12 weeks after the completion of treatment. All of the patients achieved SVR 12 (SVR rate: 100\%, 95\% Cl 97.2-100\%).

Conclusion: Hepatitis C DAA-based regimens are the effective treatments for CHC in patients with HBD, regardless of the treatment modifiers such as previous treatment experience, cirrhosis, HIV co-infection, and HCV genotype.

Keywords: Chronic hepatitis C, Direct-acting antiviral agents, Hereditary bleeding disorders, Sofosbuvir, Daclatasvir, Ledipasvir

\section{Introduction}

Hereditary bleeding disorders (HBD) are heterogeneous disorders, the most common of which are hemophilia A and B. Due to the lack of effective blood and blood product screening before 1990, many patients with HBD were

\footnotetext{
*Correspondence: alavian@thc.ir

${ }^{1}$ Middle East Liver Diseases (MELD) Center, Tehran, Iran

Full list of author information is available at the end of the article
}

infected with the hepatitis $\mathrm{C}$ virus (HCV) [1]. A metaanalysis showed that $48 \%$ of Iranian hemophilic patients were infected with $\mathrm{HCV}$ that also varies $24-89 \%$ in different countries of the world $[1,2]$. About $75-85 \%$ of patients who contracted $\mathrm{HCV}$ will develop chronic hepatitis $\mathrm{C}(\mathrm{CHC})$, which is associated with the increased risk of cirrhosis, end-stage liver diseases, and hepatocellular carcinoma [3]. HCV is also one of the leading causes of death in patients with hemophilia [4]. 
Before the 2010s, HBD patients with HCV infection were treated with pegylated interferon (Peg-IFN) plus ribavirin (RBV) [5]. Using Peg-IFN and RBV, the rate of sustained virologic response (SVR) varies from 29 to $79 \%$, which is lower in HIV-infected or HCV genotype-1 patients than in others [6]. Moreover, due to the many side-effects of these drugs and their injectable nature, many patients abandoned therapy [7]. In recent years, with the introduction of direct-acting antiviral agents (DAAs), an evolution occurred in the treatment of HBD patients with $\mathrm{HCV}$ infection, so that the SVR rate increased to $98 \%$ following the use of DAAs [8]. Hence, with advances in HCV management, the World Health Organization (WHO) decided to plan for hepatitis C elimination by 2030 [9].

Patients with HBD are excluded from many studies evaluating the effectiveness of DAAs since they were considered a particular group of patients [3]. Therefore, it is of great importance to assess the effectiveness of DAAs for the treatment of $\mathrm{HCV}$ infection in these patients, since they constitute an important group of patients with $\mathrm{CHC}$. Moreover, our knowledge about the effectiveness of DAA-based regimens for treating $\mathrm{CHC}$ in patients with HBD is limited.

Iran is one of the countries trying to eliminate $\mathrm{HCV}$, so that with $\mathrm{HCV} \mathrm{Ab}$ prevalence of $0.5 \%$ in the general population, it has the lowest prevalence of this virus in the Middle East, but the 9th place in the world in terms of the number of individuals living with hemophilia [1012]. According to Iran's national guidelines, the administration of DAAs, including sofosbuvir (SOF), daclatasvir (DCV), ledipasvir (LDV), and most recently, velpatasvir (VEL) with or without RBV, for 12 or 24 weeks is recommended for the treatment of HCV infection depending on the previous treatment experience, co-infection with HIV, and HCV genotype [10-13].

The present study aimed at evaluating the rate of SVR in Iranian patients with $\mathrm{HBD}$ and $\mathrm{CHC}$ treated with SOF-based IFN-free regimens. Efficient hepatitis $\mathrm{C}$ treatment uptake and linkage to care among patients with $\mathrm{HBD}$, one of the important groups of patients with $\mathrm{HCV}$ infection, is of great importance considering the global plan of WHO to eliminate hepatitis C by 2030 .

\section{Patients and methods}

\section{Study population and design}

The current bicentric, retrospective study was performed on patients selected from two centers of Middle-East Liver Diseases (MELD) center (Tehran, Iran) and Iranian Comprehensive Hemophilia Care Center (ICHCC) (Tehran, Iran). Patients with HBD aged above 18 years who had HCV infection for at least six months and a positive result for $\mathrm{HCV}$ RNA by RT-PCR undergoing $\mathrm{CHC}$ therapy with SOF-based IFN-free regimens from 2015 to 2019 in the two above-mentioned centers were enrolled in this study. Besides, patients co-infected with HIV, the ones with cirrhosis, and patients with a history of IFNbased therapy were also included. Patients who had previously responded to treatments such as IFN or other available options and were not treated with DAA-based regimens were excluded. Two researchers extracted the required information by evaluating patients' electronic records at MELD Center and paper-based records at ICHCC.

\section{Treatment regimens}

In Iran, SOF/DCV, SOF/LDV, and SOF/VEL were available as generic forms, and patients undergo a 12- or 24-week therapy with or without RBV, based on HCV genotype, previous treatment experience, and having cirrhosis according to national and international guidelines [10, 13-15]. From 2015 to 2019, the standard of care for the management of $\mathrm{CHC}$ had updated regularly but the common treatment discipline in these years was that patients with cirrhosis, previous treatment experience, or HCV genotype-3 need a more intensified treatment. Moreover, case-by-case clinical decisions outside the therapeutic guidelines were made by the treating physician to provide the patients desirable benefits [10-13]. HCV DAA-based regimens can be used alongside antiHIV regimens with consideration of drug-drug interactions. In this regard, DCV dose adjustment is needed considering the anti-HIV regimen [16]. Sofosbuvir interaction with anti-epileptic drugs (such as phenytoin, phenobarbital, and carbamazepine) and amiodarone was considered before starting treatment with DAA. In cases with drug-drug interactions, we consulted with their specialists to switch their treatments to remove the proposed drug-drug interaction.

\section{Liver fibrosis and laboratory assessments}

Complete blood cell count, liver enzymes, and HCV RNA using RT-PCR were performed before starting treatment, four weeks after initiation of treatment, and 12 weeks after the completion of treatment. Liver stiffness measurement (LSM) was also performed to detect cirrhosis before starting treatment. However, in cases where clinical (e.g., esophageal varices) or paraclinical (e.g., ultrasound findings) pieces of evidence were strongly in favor of cirrhosis, the LSM was ignored.

\section{Endpoints and definitions}

A patient with no history of treatment for $\mathrm{CHC}$ was called treatment-naïve. If IFN or peg-IFN is used in the previous treatment, the treatment history is considered as IFN-based treatment history, and if the previous 
treatment was IFN-free, using a combination of DAAs, it was considered as DAA-based treatment history. Patients who discontinued treatment, who did not refer during treatment, or did not test for HCV RNA, 12 weeks after the completion of treatment were called treatment discontinuation, lost to follow-up on treatment, and lost to follow-up for SVR evaluation, respectively. Moreover, conditions with undetectable results for HCV RNA four weeks after initiation of treatment and 12 weeks after the completion of treatment were called rapid virologic response (RVR) and SVR, respectively. Cases that do not reach SVR were considered a virologic treatment failure.

Our primary endpoint in the present study was to evaluate the SVR rate in patients with $\mathrm{HBD}$ and $\mathrm{CHC}$ treated with SOF-based IFN-free regimens.

\section{Statistical analysis}

All data were transferred into SPSS version 23.0 (IBM Corp.). Data obtained from quantitative variables with normal distribution were expressed as mean \pm standard deviation (SD) and those from variables that deviated from normal distribution as median and interquartile range. The Kolmogorov-Smirnov test was used to determine the normal distribution of variables. Qualitative variables were also expressed as absolute value and percentage. HCV RNA level was also expressed in logarithmic form.

\section{Results}

\section{Baseline characteristics}

A total of 147 patients with HBD and $\mathrm{CHC}$ started treatment with DAA-based regimens. The mean $( \pm S D)$ age of 147 patients was $41.1( \pm 11.6)$ years, and $94.6 \%$ were male. Six (4.1\%) patients were co-infected with HIV, and 37 (25.2\%) had cirrhosis (five with decompensated cirrhosis). HCV genotypes-1 and -3 with 98 (68.1\%) and 30 (20.8\%) patients had the highest frequency, respectively. Of these 147 patients, 113 had hemophilia A (HA), 19 had hemophilia B (HB), eight had von Willebrand disease (VWD), one had Glanzmann disorder, and six had other disorders. The median values of hemoglobin $(\mathrm{Hb}), \mathrm{AST}$, and ALT before the treatment were $15.7 \mathrm{~g} / \mathrm{dL}, 38 \mathrm{IU} / \mathrm{L}$, and $42 \mathrm{IU} / \mathrm{L}$, respectively. The mean HCV RNA level at baseline was $6.0 \log _{10} \mathrm{IU} / \mathrm{mL}$ (Table 1 ). The anti-HIV regimens in the 6 patients with HIV-HCV co-infection were zidovudine + lamivudine + efavirenz (two patients), tenofovir + lamivudine + efavirenz (two patients), lopinavir/ritonavir + efavirenz (one patient), and lopinavir/ ritonavir + lamivudine + tenofovir (one patient). Five patients with HIV-HCV co-infection were treated with $\mathrm{SOF} / \mathrm{LDV} \pm \mathrm{RBV}$ that did not need a dose adjustment. However, one patient with HIV-HCV co-infection was subjected to DCV dose adjustment from standard $60 \mathrm{mg}$ dose to $90 \mathrm{mg}$ dose. The baseline characteristics except for the type of HBD $(P<0.05)$ were not different between patients who were evaluated for SVR and patients with treatment discontinuation or loss to follow-up (Table 1).

\section{Antiviral response}

Treatment with DAA-based regimens was started for 147 patients with HBD and CHC. One patient discontinued the treatment arbitrarily after one month, with no side effects. Moreover, 9 patients did not refer during the treatment course, and it was not clear whether they completed the treatment or not. Five patients completed the treatment course but did not refer 12 weeks after treatment completion to determine SVR. The remaining 132 patients completed the treatment and were available for the evaluation of SVR (Fig. 1). Of the 147 patients who received DAA-based treatment, SOF/LDV + RBV was the most common regimen administered to $53(36.1 \%)$ patients. SOF/LDV and $\mathrm{SOF} / \mathrm{DCV} \pm \mathrm{RBV}$ regimens were other common regimens in this study. The regimens, treatment courses (12 or 24 weeks), and RVR and SVR rates are shown in Table 2. Regardless of HCV genotype, therapeutic regimen, HIV co-infection, liver disease status, and HCV RNA level at baseline, the HCV RNA was undetectable in all the 132 patients, 12 weeks after treatment completion (SVR rate: 100\%, 95\% CI 97.2-100\%). Of these 132 patients, HCV RNA was evaluated on blood samples of 100 patients four weeks after the treatment initiation, of which only six were detectable, who finally achieved SVR. The characteristics of these six patients that didn't achieve RVR are shown in Table 3. Of the 15 patients whose SVR status was unknown due to the reasons stated, HCV RNA detection was performed on the blood samples of nine of them, four weeks after the treatment initiation, which all were undetectable. Therefore, the overall RVR rate was $94.5 \%$ (95 CI 88.4$98.0 \%$ ) in the present study (Table 2).

\section{Treatment side-effects}

Among 132 patients with follow-up, none expired during treatment or 12 weeks after treatment termination, and no significant side-effect causing treatment discontinuation was observed. In three patients that treatment was commenced with RBV, due to gastrointestinal bleeding, RBV was removed from the treatment course. Despite the removal of RBV from treatment, all of these three patients achieved RVR and SVR. Week- 4 Hb reduction was more prominent in patients treated with RBV (38.1\% with $>2 \mathrm{~g} / \mathrm{dL}$ Hb decline) than those who did not receive RBV (3.2\% with $>2 \mathrm{~g} / \mathrm{dL}$ Hb decline). 
Table 1 Baseline characteristics of patients

\begin{tabular}{|c|c|c|c|}
\hline Characteristics & All patients $(\mathrm{N}=147)$ & $\begin{array}{l}\text { Patients who were } \\
\text { evaluated for SVR } \\
(\mathrm{N}=132)\end{array}$ & $\begin{array}{l}\text { Patients with treatment } \\
\text { discontinuation or loss to } \\
\text { follow-up }(\mathrm{N}=15)\end{array}$ \\
\hline Age $^{*}$, mean $\pm S D$ (years) & $41.1 \pm 11.6$ & $41.2 \pm 11.9$ & $40.1 \pm 8.7$ \\
\hline \multicolumn{4}{|l|}{ Gender, n (\%) } \\
\hline Male & $139(94.6 \%)$ & $126(95.5 \%)$ & $13(86.7 \%)$ \\
\hline Female & $8(5.4 \%)$ & $6(4.5 \%)$ & $2(13.3 \%)$ \\
\hline \multicolumn{4}{|l|}{ Hereditary bleeding disorder types, n (\%) } \\
\hline Hemophilia A & $113(76.9 \%)$ & $106(80.3 \%)$ & $7(46.7 \%)$ \\
\hline Hemophilia B & $19(12.9 \%)$ & $14(10.6 \%)$ & $5(33.3 \%)$ \\
\hline VWD & $8(5.4 \%)$ & $6(4.5 \%)$ & $2(13.3 \%)$ \\
\hline Glanzmann & $1(0.7 \%)$ & $1(0.8 \%)$ & $0(0 \%)$ \\
\hline Other disorders & $6(4.1 \%)$ & $5(3.8 \%)$ & $1(6.7 \%)$ \\
\hline HIV co-infection, n (\%) & $6(4.1 \%)$ & $5(3.8 \%)$ & $1(6.7 \%)$ \\
\hline HBV co-infection, n (\%) & $0(0 \%)$ & $0(0 \%)$ & $0(0 \%)$ \\
\hline Platelet count**, mean $\pm S D\left(10^{9} / \mathrm{L}\right)$ & $200.0 \pm 59.3$ & $197.8 \pm 59.4$ & $219.8 \pm 56.6$ \\
\hline Hemoglobin**, Median (IQR) (g/dL) & $15.7(14.3-16.9)$ & $15.7(14.4-16.9)$ & $15.3(11.1-17.3)$ \\
\hline $\mathrm{AST}^{* *}$, Median (IQR) (IU/L) & $38(27-55)$ & $38(27-55)$ & $38(32-76)$ \\
\hline $\mathrm{ALT}^{* *}$, Median (IQR) (IU/L) & $42(27-70)$ & $42(30-70)$ & $46(19-72.5)$ \\
\hline HCV RNA*, mean $\pm S D\left(\log _{10} \mid \mathrm{U} / \mathrm{mL}\right)$ & $6.0 \pm 0.8$ & $5.9 \pm 0.8$ & $6.2 \pm 0.5$ \\
\hline \multicolumn{4}{|c|}{ Liver stiffness measurement (Metavir score)* $\mathrm{n}(\%)$} \\
\hline F0-F2 & $75(54 \%)$ & $66(52.8 \%)$ & $9(64.3 \%)$ \\
\hline F2-F4 & $33(23.7 \%)$ & $31(24.8 \%)$ & $2(14.3 \%)$ \\
\hline F4 & $31(22.3 \%)$ & $28(22.4 \%)$ & $3(21.4 \%)$ \\
\hline \multicolumn{4}{|l|}{ Cirrhosis, n (\%) } \\
\hline Non-cirrhotic & $110(74.8 \%)$ & $99(75 \%)$ & $11(73.3 \%)$ \\
\hline Compensated cirrhosis & $32(21.8 \%)$ & $29(22.0 \%)$ & $3(20 \%)$ \\
\hline Decompensated cirrhosis & $5(3.4 \%)$ & $4(3.0 \%)$ & $1(6.7 \%)$ \\
\hline \multicolumn{4}{|l|}{ HCV genotype ${ }^{*}, n(\%)$} \\
\hline 1 & $98(68.1 \%)$ & $89(68.5 \%)$ & $9(64.3 \%)$ \\
\hline 2 & $2(1.4 \%)$ & $2(1.5 \%)$ & $0(0 \%)$ \\
\hline 3 & $30(20.8 \%)$ & $27(20.8 \%)$ & $3(21.4 \%)$ \\
\hline 4 & $4(2.8 \%)$ & $4(3.1 \%)$ & $0(0 \%)$ \\
\hline Mix & $10(6.9 \%)$ & $8(6.1 \%)$ & $2(14.3 \%)$ \\
\hline \multicolumn{4}{|l|}{ Previous treatment experience, $\mathrm{n}(\%)$} \\
\hline Treatment naïve & $68(46.3 \%)$ & $61(46.2 \%)$ & $7(46.7 \%)$ \\
\hline Interferon-experienced & $79(53.7 \%)$ & $71(53.8 \%)$ & $8(53.3 \%)$ \\
\hline DAA-experienced & $0(0 \%)$ & $0(0 \%)$ & $0(0 \%)$ \\
\hline
\end{tabular}

$S D$ standard deviation, IQR interquartile range, DAA direct-acting antiviral agent, VWDVon Willebrand disease, SVR sustained virologic response, $n$ number, HIV human immunodeficiency virus, $H B V$ hepatitis B virus, $A L T$ alanine aminotransferase, AST aspartate aminotransferase

* Data were missed in less than $10 \%$ of patients

** Data were missed in more than $10 \%$ of patients

\section{Discussion}

Patients with HBD and $\mathrm{CHC}$ were considered as difficultto-treat due to co-infection with HIV, more advanced liver diseases due to prolonged $\mathrm{HCV}$ infection, predominance of the male gender, and predominance of HCV genotype-1, all are SVR-reducing parameters in patients undergoing peg-IFN therapy $[6,17,18]$. An evolution occurred in the treatment of patients with $\mathrm{CHC}$ following the introduction of DAAs. Subsequently, in May 2016, the hepatitis C elimination plan was described by $\mathrm{WHO}$ to reduce active cases of $\mathrm{HCV}$ infection by $80 \%$ and a $65 \%$ reduction in HCV-related death by 2030 [9]. In 2017, The European Association for the Study of the Liver (EASL) defined a new term called micro-elimination. In the micro-elimination approach, patients were divided into smaller groups to get prevention, care, and 
147 hereditary bleeding disorder patients with chronic hepatitis $\mathrm{C}$ started interferon-free treatment

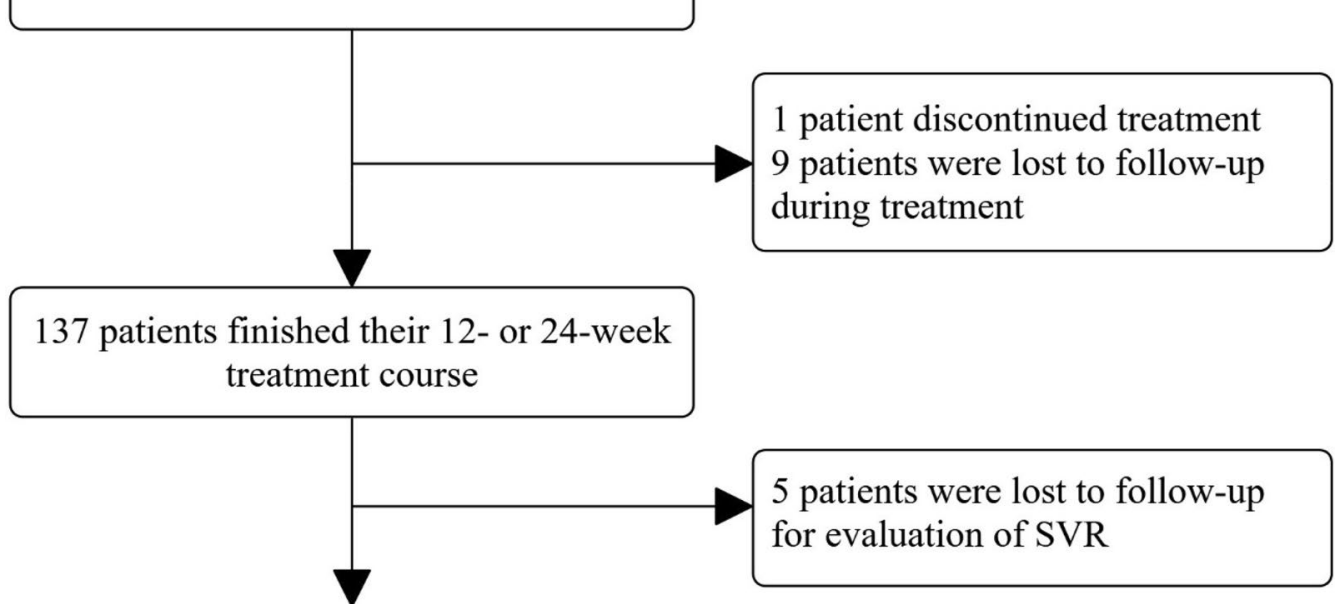

132 patients were evaluated for SVR 12 weeks after treatment

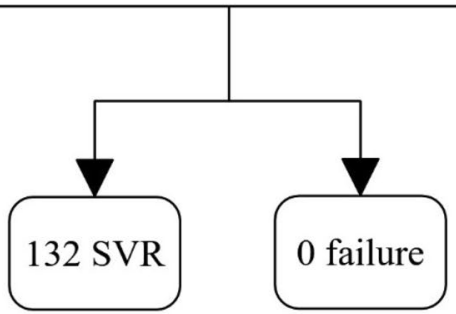

Fig. 1 Flowchart of hepatitis $C$ treatment

treatment faster and more effectively. Incarcerated individuals, HBD patients, and people who inject drugs are examples of $\mathrm{HCV}$ micro-elimination subgroups. This method will be useful to get the WHO program to eliminate HCV [19].

European Association for the Study of the Liver, American Association for the Study of the Liver Diseases (AASLD), and Infectious Diseases Society of America (IDSA) recommended therapeutic regimens consisting of SOF+DCV, SOF/LDV, SOF/VEL, SOF/VEL/VOX (voxilaprevir), glecaprevir/pibrentasvir (GLE/PIB), elbasvir/grazoprevir (EBR/GZR), and SOF +EBR/GZR with or without RBV for 8,12 or 24 weeks $[16,20]$. The SVR rate reaches $90-99 \%$ by taking these regimens [21-25]. Sofosbuvir, an NS5B polymerase inhibitor, plus an NS5A inhibitor, available as LDV, DCV, and VEL, is prescribed in Iran to treat $\mathrm{CHC}$ for 12 or 24 weeks with or without RBV [13]. The SVR rates yielded following these regimens were reported $96.7-100 \%$ in Iran [26-28].
Nine studies from Belgium, the USA, Japan, South Korea, New Zealand, Italy, China, and Portugal thus far measured SVR rate in patients with HBD and $\mathrm{CHC}$; except two studies from the United States and Italy, as well as the present study, their sample sizes were less than $100[3,7,17,29-34]$. The information of these studies is summarized in Table 4.

Fransen et al. [29] performed a study in Belgium on 85 patients with HBD and CHC treated with DAAs. Of these 85 patients, the SVR rate was measured in 84 , and 77 (91.6\%) achieved SVR. All the seven patients not reaching SVR were HCV genotype-1b, treatment-naïve, and non-cirrhotic. Five patients were treated with EBR/ GZR, one with ombitasvir (OBV)/ritonavir (r)/paritaprevir (PTV) \pm dasabuvir (DSV), and one with SOF/ VEL. Walsh et al. [3] conducted a study on 120 patients with HBD and CHC treated with DAAs. The SOF/LDV regimen was administered to 104 patients with $\mathrm{HCV}$ genotype-1 or -4 . 10 patients with $\mathrm{HCV}$ genotype- 2 and 
Table 2 Treatment regimens and antiviral response

\begin{tabular}{|c|c|c|c|c|c|c|c|}
\hline \multirow[t]{3}{*}{ Regimen } & \multirow{3}{*}{$\begin{array}{l}\text { All patients } \\
(\mathrm{N}=147)\end{array}$} & \multirow{3}{*}{$\begin{array}{l}\text { Patients who } \\
\text { were evaluated } \\
\text { for SVR }(N=132)\end{array}$} & \multirow{3}{*}{$\begin{array}{l}\text { Patients with } \\
\text { treatment } \\
\text { discontinuation } \\
\text { or loss to } \\
\text { follow-up }(\mathrm{N}=15)\end{array}$} & \multicolumn{4}{|c|}{ Virologic responses } \\
\hline & & & & \multicolumn{2}{|l|}{$\operatorname{RVR}(\mathrm{N}=109)$} & \multicolumn{2}{|l|}{$\operatorname{SVR}(N=132)$} \\
\hline & & & & Rate (\%) & $95 \% \mathrm{Cl}$ of $\% *$ & Rate (\%) & $95 \% \mathrm{Cl}$ of $\% *$ \\
\hline SOF/LDV $12 \mathrm{~W}$ & $32(21.8 \%)$ & $30(22.7 \%)$ & $2(13.3 \%)$ & 15/16 (93.8\%) & $69.8-99.8 \%$ & $30 / 30(100 \%)$ & $88.4-100 \%$ \\
\hline SOF/LDV $24 \mathrm{~W}$ & $9(6.1 \%)$ & $7(5.3 \%)$ & $2(13.3 \%)$ & $9 / 9(100 \%)$ & $66.4-100 \%$ & 7/7 (100\%) & $59.0-100 \%$ \\
\hline $\begin{array}{l}\text { SOF/LDV + RBV } \\
12 \mathrm{~W}\end{array}$ & $46(31.3 \%)$ & $42(31.8 \%)$ & $4(26.6 \%)$ & $39 / 41(95.1 \%)$ & $83.5-99.4 \%$ & $42 / 42(100 \%)$ & $91.6-100 \%$ \\
\hline $\begin{array}{l}\text { SOF/LDV + RBV } \\
24 \mathrm{~W}\end{array}$ & $7(4.8 \%)$ & $6(4.5 \%)$ & $1(6.7 \%)$ & $3 / 6(50 \%)$ & $11.8-88.2 \%$ & $6 / 6(100 \%)$ & $54.1-100 \%$ \\
\hline SOF/DCV $12 \mathrm{~W}$ & $22(15 \%)$ & $20(15.1 \%)$ & $2(13.3 \%)$ & 14/14 (100\%) & $76.9-100 \%$ & $20 / 20(100 \%)$ & $83.2-100 \%$ \\
\hline SOF/DCV $24 \mathrm{~W}$ & 4 (2.7\%) & $3(2.3 \%)$ & $1(6.7 \%)$ & $2 / 2(100 \%)$ & $15.8-100 \%$ & $3 / 3(100 \%)$ & $29.2-100 \%$ \\
\hline $\begin{array}{l}\text { SOF/DCV + RBV } \\
12 \mathrm{~W}\end{array}$ & $5(3.4 \%)$ & $4(3.1 \%)$ & $1(6.7 \%)$ & $3 / 3(100 \%)$ & $29.2-100 \%$ & $4 / 4(100 \%)$ & $39.8-100 \%$ \\
\hline $\begin{array}{l}\text { SOF/DCV + RBV } \\
24 \mathrm{~W}\end{array}$ & $13(8.8 \%)$ & $12(9.1 \%)$ & $1(6.7 \%)$ & 13/13 (100\%) & $75.3-100 \%$ & $12 / 12(100 \%)$ & $73.5-100 \%$ \\
\hline SOF/NEL $12 \mathrm{~W}$ & $7(4.7 \%)$ & $7(5.3 \%)$ & $0(0 \%)$ & $4 / 4(100 \%)$ & $39.8-100 \%$ & $7 / 7(100 \%)$ & $59.0-100 \%$ \\
\hline SOF/NEL $24 \mathrm{~W}$ & $1(0.7 \%)$ & $0(0 \%)$ & $1(6.7 \%)$ & NA & NA & NA & NA \\
\hline SOF + RBV $24 \mathrm{~W}$ & $1(0.7 \%)$ & $1(0.8 \%)$ & $0(0 \%)$ & $1 / 1(100 \%)$ & $2.5-100 \%$ & $1 / 1(100 \%)$ & $2.5-100 \%$ \\
\hline Total & $147(100 \%)$ & $132(100 \%)$ & $15(100 \%)$ & $103 / 109$ (94.5\%) & $88.4-98.0 \%$ & $132 / 132(100 \%)$ & $97.2-100 \%$ \\
\hline
\end{tabular}

SOF sofosbuvir, LDV ledipasvir, DCV daclatasvir, VEL velpatasvir, $R B V$ ribavirin, $W$ weeks, $R V R$ rapid virologic response, SVR sustained virologic response, NA not available, $\mathrm{Cl}$ confidence interval, $\mathrm{N}$ number

*Binomial exact calculation

six patients with $\mathrm{HCV}$ genotype-3 were treated with SOF + RBV. Among all 104 patients receiving SOF/LDV, except one who was lost to follow-up, others achieved SVR. Moreover, all 10 patients with HCV genotypes-2 and five (83\%) patients with HCV genotype-3 achieved SVR. The study by Nagao et al. [31] in Japan treated 43 patients with hemophilia and CHC using SOF/LDV for 12 weeks. In this study, $96 \%$ of the patients achieved SVR, and the SVR rate was significantly different between cirrhotic and non-cirrhotic patients $(78 \%$ for cirrhotic and $100 \%$ for non-cirrhotic patients, $P$ value $=0.005)$. Mancuso et al. [17] conducted a study in Italy on 200 patients, $61 \%$ of whom underwent the SOF-based treatment and $20 \%$ treated with GLE/PIB regimen. Only two patients didn't achieve SVR that both were HIV-positive. In the above-mentioned study, the SVR rate of HIV-negative patients was significantly higher than that of HIV-positive ones $(100 \%$ vs. $95 \%$; $P$ value $=0.04)$.

In the present study, 147 patients with $\mathrm{HBD}$ and $\mathrm{CHC}$ underwent $\mathrm{SOF} / \mathrm{LDV} \pm \mathrm{RBV}, \quad \mathrm{SOF} / \mathrm{DCV} \pm \mathrm{RBV}, \quad \mathrm{SOF} /$ $\mathrm{VEL}$, and SOF $+\mathrm{RBV}$ regimens. 132 patients completed the treatment course, their SVR rate was measured, and all achieved SVR. The present study, following the study by Mancuso et al. [17], had the largest sample size with an SVR rate of $100 \%$, which was similar to those of other studies (91.6-100\%). While $94.5 \%$ of patients achieved RVR, all those without RVR had undetectable HCV
RNA, 12 weeks after treatment termination (SVR). This confirms that on-treatment response (RVR) has no or little impact on treatment success (SVR) as proposed in a study by Kowdley et al. [35].

The pandemics of coronavirus disease 2019 (COVID19) impacted the containment of other infectious diseases such as HCV care and elimination in Iran and worldwide. With the ongoing condition, there is a great concern regarding the achievement of WHO elimination goals [36]. Moreover, initiating HCV antiviral therapy in patients with current COVID-19 infection is not warranted [37].

The present study had some strengthens over the past studies such as a larger sample size in comparison to most of the previous studies. Moreover, the drugs were used in this study were generics that showed the same efficacy as those of brand-name drugs. The limitations of the current study were its retrospective design and evaluation of only the therapeutic regimens (SOF-based regimens) available in Iran.

\section{Conclusion}

Our study showed that DAAs are highly effective in HBD patients for the treatment of HCV infection, irrespective of the treatment modifiers such as previous treatment experience, cirrhosis, HIV co-infection, and $\mathrm{HCV}$ genotype. These results demonstrated that we 


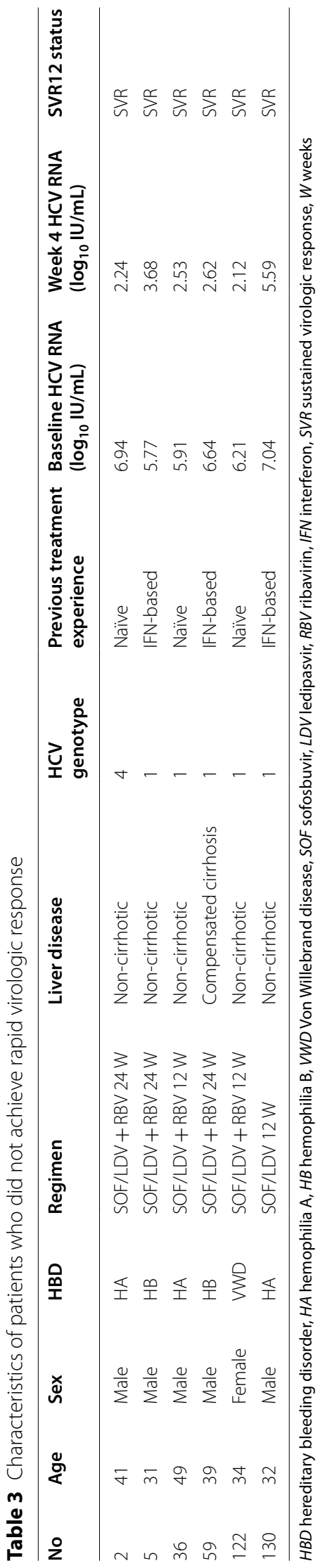


Table 4 Literature review of studies on the efficacy of IFN-free regimens in hereditary bleeding disorder patients with HCV infection

\begin{tabular}{|c|c|c|c|c|c|c|c|c|c|}
\hline Author & Study date & $\begin{array}{l}\text { Study } \\
\text { location }\end{array}$ & $\begin{array}{l}\text { Sample } \\
\text { size, } \mathrm{n}\end{array}$ & $\begin{array}{l}\text { Anti-HCV } \\
\text { regimen, \% }\end{array}$ & $\begin{array}{l}\text { HCV } \\
\text { genotype, \% }\end{array}$ & $\begin{array}{l}\text { Treatment } \\
\text { naïve, } \%\end{array}$ & $\begin{array}{l}\text { HIV } \\
\text { co-infection, } \\
\%\end{array}$ & Cirrhosis, \% & SVR \\
\hline \multirow{8}{*}{$\begin{array}{l}\text { Fransen et al. } \\
\text { [29] }\end{array}$} & \multirow[t]{8}{*}{2019} & \multirow[t]{8}{*}{ Belgium } & \multirow[t]{8}{*}{85} & SOF/LDV: $2.4 \%$ & $N A^{*}$ & \multirow[t]{8}{*}{72.6} & \multirow[t]{8}{*}{$N A^{*}$} & \multirow[t]{8}{*}{12} & \multirow[t]{8}{*}{ 77/84 (91.6\%) } \\
\hline & & & & SOFNEL: $16.4 \%$ & & & & & \\
\hline & & & & SOF + SIM: 5.9\% & & & & & \\
\hline & & & & SOF+DCV: $12.9 \%$ & & & & & \\
\hline & & & & $\begin{array}{l}\text { OBV/r/PTV } \pm \text { DSV: } \\
20.0 \%\end{array}$ & & & & & \\
\hline & & & & EBR/GZR: 21.2\% & & & & & \\
\hline & & & & GLE/PIB: 12.9\% & & & & & \\
\hline & & & & Others ${ }^{* *}: 8.2 \%$ & & & & & \\
\hline \multirow[t]{6}{*}{ Walsh et al. [3] } & \multirow[t]{6}{*}{2017} & \multirow[t]{6}{*}{ US } & \multirow[t]{6}{*}{120} & SOF/LDV: 86.7\% & $1: 0.8 \%$ & \multirow[t]{6}{*}{60} & \multirow[t]{6}{*}{$21.7 \%$} & \multirow[t]{6}{*}{30.8} & \multirow[t]{6}{*}{ 118/120 (98.3\% } \\
\hline & & & & SOF + RBV: $13.3 \%$ & 1a: $59.2 \%$ & & & & \\
\hline & & & & & 1b: $25.9 \%$ & & & & \\
\hline & & & & & $2: 8.3 \%$ & & & & \\
\hline & & & & & $3: 5 \%$ & & & & \\
\hline & & & & & $4: 0.8 \%$ & & & & \\
\hline \multirow[t]{4}{*}{ Nagao et al. [31] } & \multirow[t]{4}{*}{2017} & \multirow[t]{4}{*}{ Japan } & \multirow[t]{4}{*}{43} & \multirow[t]{4}{*}{ SOF/LDV: 100\% } & 1a: $58.1 \%$ & \multirow[t]{4}{*}{58.1} & \multirow[t]{4}{*}{$46.5 \%$} & 20.9 & $41 / 43(95.3 \%)$ \\
\hline & & & & & 1b: $27.9 \%$ & & & & \\
\hline & & & & & $1 a+2 b: 2.3 \%$ & & & & \\
\hline & & & & & $4: 11.7 \%$ & & & & \\
\hline Lee et al. [7] & 2017 & Korea & 30 & DCV + ASV: 60\% & 1b: 70\% & 70 & NR & 13.3 & 28/30 (93.3\%) \\
\hline & & & & LDV/SOF: $26.7 \%$ & 1a: $16.7 \%$ & & & & \\
\hline & & & & SOF + RBV: $13.3 \%$ & $2 \mathrm{a} / 2 \mathrm{~b}: 13.3 \%$ & & & & \\
\hline Stedman et al. & 2016 & New Zealand & 14 & SOF/LDV + RBV: & 1a: $71 \%$ & 79 & $0 \%$ & 7 & 14/14 (100\%) \\
\hline & & & & $100 \%$ & 1b: $29 \%$ & & & & \\
\hline Mancuso et al. & 2020 & Italy & 200 & SOF/NEL: $22.5 \%$ & 1a: $63 \%$ & 54 & $20 \%$ & 28 & 198/200 (99\%) \\
\hline & & & & GLE/PIB: 20\% & 1b: $15 \%$ & & & & \\
\hline & & & & SOF/LDV: $11.5 \%$ & $1: 1 \%$ & & & & \\
\hline & & & & $\begin{array}{l}\text { SOF/LDV + RBV: } \\
10 \%\end{array}$ & $2: 12 \%$ & & & & \\
\hline & & & & SOF+SIM: $6.5 \%$ & $3: 7 \%$ & & & & \\
\hline & & & & GZR/EBR: $6.5 \%$ & 4: $3 \%$ & & & & \\
\hline & & & & $\begin{array}{l}\text { DSV/PTV/OBV/r: } \\
5.5 \%\end{array}$ & & & & & \\
\hline & & & & $\begin{array}{l}\text { DSV/PTV/ } \\
\text { OBV/r+RBV: } 5 \%\end{array}$ & & & & & \\
\hline & & & & $\begin{array}{l}\text { SOF + DCV + RBV: } \\
4 \%\end{array}$ & & & & & \\
\hline & & & & $\mathrm{DCV}+\mathrm{RBV}: 2.5 \%$ & & & & & \\
\hline & & & & SOF + DCV: $2 \%$ & & & & & \\
\hline & & & & SOF + RBV: $1.5 \%$ & & & & & \\
\hline & & & & $\begin{array}{l}\text { SOF/NEL + RBV: } \\
1.5 \%\end{array}$ & & & & & \\
\hline & & & & $\begin{array}{l}\text { SOF + SIM + RBV: } \\
1 \%\end{array}$ & & & & & \\
\hline Xiao et al. [34] & 2019 & China & 12 & SOF + DCV: $66.7 \%$ & 1b: $75 \%$ & 41.7 & $100 \%$ & 33 & $12 / 12(100 \%)$ \\
\hline & & & & SOF/NEL: $16.7 \%$ & 2i: $16.7 \%$ & & & & \\
\hline & & & & SOF + RBV: $8.3 \%$ & $3: 8.3 \%$ & & & & \\
\hline & & & & DCV + ASV: $8.3 \%$ & & & & & \\
\hline
\end{tabular}


Table 4 (continued)

\begin{tabular}{|c|c|c|c|c|c|c|c|c|c|}
\hline Author & Study date & $\begin{array}{l}\text { Study } \\
\text { location }\end{array}$ & $\begin{array}{l}\text { Sample } \\
\text { size, } n\end{array}$ & $\begin{array}{l}\text { Anti-HCV } \\
\text { regimen, \% }\end{array}$ & $\begin{array}{l}\text { HCV } \\
\text { genotype, \% }\end{array}$ & $\begin{array}{l}\text { Treatment } \\
\text { naïve, \% }\end{array}$ & $\begin{array}{l}\text { HIV } \\
\text { co-infection, } \\
\%\end{array}$ & Cirrhosis, \% & SVR \\
\hline \multirow{6}{*}{$\begin{array}{l}\text { Uemura et al. } \\
\text { [33] }\end{array}$} & \multirow[t]{6}{*}{2017} & \multirow[t]{6}{*}{ Japan } & \multirow[t]{6}{*}{27} & SOF/LDV: $85.2 \%$ & 1a: $15 \%$ & \multirow[t]{6}{*}{33} & \multirow[t]{6}{*}{$100 \%$} & \multirow[t]{6}{*}{41} & \multirow[t]{6}{*}{$27 / 27(100 \%)$} \\
\hline & & & & SOF+RBV: $3.7 \%$ & 1b: 59\% & & & & \\
\hline & & & & \multirow[t]{4}{*}{ SOF+DCV: $11.1 \%$} & $1: 7 \%$ & & & & \\
\hline & & & & & 2a: $4 \%$ & & & & \\
\hline & & & & & 3a: $11 \%$ & & & & \\
\hline & & & & & 4a: 4\% & & & & \\
\hline \multirow{5}{*}{$\begin{array}{l}\text { Guedes et al. } \\
\text { [30] }\end{array}$} & \multirow[t]{5}{*}{2020} & \multirow[t]{5}{*}{ Portugal } & \multirow[t]{5}{*}{16} & SOF/LDV: $75 \%$ & 1a: 40\% & \multirow[t]{5}{*}{12.5} & \multirow[t]{5}{*}{ NR } & \multirow[t]{5}{*}{62.5} & \multirow[t]{5}{*}{ 16/16 (100\%) } \\
\hline & & & & $\begin{array}{l}\text { SOF/LDV + RBV: } \\
6.25 \%\end{array}$ & $1 \mathrm{~b}: 46.6 \%$ & & & & \\
\hline & & & & SOF + RBV: $6.25 \%$ & $2: 6.7 \%$ & & & & \\
\hline & & & & $\begin{array}{l}\text { OBV/PTV/r+DSV: } \\
6.25 \%\end{array}$ & 3a: $6.7 \%$ & & & & \\
\hline & & & & EBR/GZR: $6.25 \%$ & & & & & \\
\hline \multirow[t]{6}{*}{ Current study } & \multirow[t]{6}{*}{2020} & \multirow[t]{6}{*}{ Iran } & \multirow[t]{6}{*}{147} & SOF/LDV: $27.9 \%$ & $1: 68.1 \%$ & \multirow[t]{6}{*}{46.3} & \multirow[t]{6}{*}{$4.1 \%$} & \multirow[t]{6}{*}{25.2} & \multirow[t]{6}{*}{$132 / 132(100 \%)$} \\
\hline & & & & $\begin{array}{l}\text { SOF/LDV + RBV: } \\
36.1 \%\end{array}$ & 2: $1.4 \%$ & & & & \\
\hline & & & & SOF/DCV: $17.7 \%$ & $3: 20.8 \%$ & & & & \\
\hline & & & & $\begin{array}{l}\text { SOF/DCV+RBV: } \\
12.2 \%\end{array}$ & $4: 2.8 \%$ & & & & \\
\hline & & & & SOF/VEL: 5.4\% & Mix: 6.9\% & & & & \\
\hline & & & & SOF+RBV: $0.7 \%$ & & & & & \\
\hline
\end{tabular}

NR not reported, NA not available, DSV dasabuvir, EBR elbasvir, GLE glecaprevir, GZR grazoprevir, LDV ledipasvir, OBV ombitasvir, VEL velpatasvir, VOX voxilaprevir, DCV daclatasvir, ASV asunaprevir, SIM simprevir, PTV paritaprevir, PIB pibrenastavir, $r$ ritonavir, SVR sustained virologic response, HIV human immunodeficiency virus

* The HCV genotyping and HIV co-infection data were reported for total cases, not patients who received DAAs

** Not mentioned in the article

can take steps toward HCV micro-elimination in HBD patients in line with the WHO HCV elimination program in 2030.

\section{Abbreviations}

CHC: Chronic hepatitis C; HBD: Hereditary bleeding disorders; DAA: Directacting antiviral agent; SVR: Sustained virologic response; HCV: Hepatitis C virus; RBV: Ribavirin; SOF: Sofosbuvir; DCV: Daclatasvir; LDV: Ledipasvir; VEL: Velpatasvir; RVR: Rapid virologic response; EASL: European association for the study of the liver; AASLD: American association for the study of the liver diseases; IDSA: Infectious diseases society of America; VOX: Voxilaprevir; GLE/ PIB: Glecaprevir/pibrentasvir; EBR/GZR: Elbasvir/grazoprevir; OBV: Ombitasvir; r: Ritonavir; PTV: Paritaprevir; DSV: Dasabuvir.

\section{Acknowledgements}

Not applicable.

\section{Authors' contributions}

HS and SMA designed the study. Data were collected by AAS, AA, AN, and SS $\mathrm{HS}$ analyzed data. HS, BB, ands SMA wrote the article. The final edit was done by SMA and HS. All authors read and approved the final manuscript.

\section{Funding}

Not applicable.

\section{Availability of data and materials}

The datasets used and/or analyzed during the current study are available from the corresponding author on reasonable request.

\section{Declarations}

Ethics approval and consent to participate

The study was reviewed and approved by the Ethics Committee of Baqiyatallah University of Medical Sciences (ethical code: IR.BMSU.REC.1398.145). Besides, due to the retrospective nature of the study, informed consent was inapplicable.

\section{Consent for publication}

Not applicable.

\section{Competing interests}

The authors stated that they had no interests which might be perceived as posing a conflict or bias.

\section{Author details}

${ }^{1}$ Middle East Liver Diseases (MELD) Center, Tehran, Iran. ${ }^{2}$ Iranian Comprehensive Haemophilia Care Centre, Tehran, Iran. ${ }^{3}$ Baqiyatallah Research Center for Gastroenterology and Liver Diseases (BRCGL), Baqiyatallah University of Medical Sciences, Tehran, Iran.

Received: 15 June 2021 Accepted: 14 September 2021

Published online: 07 October 2021

\section{References}

1. Papadopoulos N, Argiana V, Deutsch M. Hepatitis C infection in patients with hereditary bleeding disorders: epidemiology, natural history, and management. Ann Gastroenterol. 2018;31(1):35. 
2. Alavian SM, Aalaei-Andabili SH. Lack of knowledge about hepatitis C infection rates among patients with inherited coagulation disorders in countries under the Eastern Mediterranean Region Office of WHO (EMRO): a meta-analysis. Hepat Mon. 2012;12(4):244.

3. Walsh C, Workowski K, Terrault N, Sax P, Cohen A, Bowlus C, et al. Ledipasvir-sofosbuvir and sofosbuvir plus ribavirin in patients with chronic hepatitis C and bleeding disorders. Haemophilia. 2017:23(2):198-206.

4. Tagliaferri A, Rivolta G, Iorio A, Oliovecchio E, Mancuso M, Morfini M, et al. Mortality and causes of death in Italian persons with haemophilia, 1990-2007. Haemophilia. 2010;16(3):437-46.

5. Keshvari M, Alavian SM, Behnava B, Pouryasin A, Craig JC, Sharafi H. Impact of IFNL 4 rs12979860 and rs8099917 polymorphisms on response to Peg-Interferon- $a$ and Ribavirin in patients with congenital bleeding disorder and chronic hepatitis C. J Clin Lab Anal. 2017;31(4):e22063.

6. Franchini M, Mengoli C, Veneri D, Mazzi R, Lippi G, Cruciani M. Treatment of chronic hepatitis $C$ in haemophilic patients with interferon and ribavirin: a meta-analysis. J Antimicrob Chemother. 2008;61(6):1191-200.

7. Lee HW, Yoo KY, Won JW, Kim HJ. Direct acting antiviral agents in Korean patients with chronic hepatitis $C$ and hemophilia who are treatmentnaïve or treatment-experienced. Gut Liver. 2017;11(5):721.

8. Perazzo H, Castro R, Luz PM, Banholi M, Goldenzon RV, Cardoso SW, et al. Effectiveness of generic direct-acting agents for the treatment of hepatitis C: systematic review and meta-analysis. Bull World Health Organ. 2020:98(3):188.

9. World Health Organization. Global health sector strategy on viral hepatitis 2016-2021 2016. Available from: https://apps.who.int/iris/bitstream/ handle/10665/246177/WHO-HIV-2016.06-eng.pdf? sequence=1.

10. Alavian SM, Hajarizadeh B, Lankarani KB, Sharafi H, Daryani NE, Merat $\mathrm{S}$, et al. Recommendations for the clinical management of hepatitis $C$ in Iran: a consensus-based national guideline. Hepat Mon. 2016:16(8):e40959.

11. Dorgalaleh A, Dadashizadeh G, Bamedi T. Hemophilia in Iran. Hematology. 2016;21(5):300-10.

12. Gower E, Estes C, Blach S, Razavi-Shearer K, Razavi H. Global epidemiology and genotype distribution of the hepatitis $C$ virus infection. J Hepatol. 2014;61(1):S45-57.

13. Alavian SM, Sharafi H. Update on recommendations for the clinical management of hepatitis C in Iran 2017. Hepat Mon. 2017;17(11):4.

14. European Association for the Study of the Liver 2017. EASL recommendations on treatment of hepatitis C 2015. J Hepatol. 2015;63(1):199-236.

15. European Association for the Study of the Liver. EASL recommendations on treatment of hepatitis C 2016. J Hepatol. 2017;66(1):153-94.

16. European Association for the Study of the Liver. EASL recommendations on treatment of hepatitis C 2018. J Hepatol. 2018;69(2):461-511.

17. Mancuso ME, Linari S, Santagostino E, Bartolozzi D, D'Ambrosio R, Borghi $M$, et al. High rate of sustained virological response with direct-acting antivirals in haemophiliacs with HCV infection: a multicenter study. Liver Int. 2020;40(5):1062-8.

18. Keshvari M, Alavian SM, Behnava B, Pouryasin A, Sharafi H. The interferon lambda 4 rs368234815 predicts treatment response to pegylated-interferon alpha and ribavirin in hemophilic patients with chronic hepatitis C. J Res Med Sci Off J Isfahan Univ Med Sci. 2016;21:72.

19. Lazarus JV, Wiktor S, Colombo M, Thursz M. Micro-elimination-A path to global elimination of hepatitis C. J Hepatol. 2017;67(4):665-6.

20. Hepatitis C. guidance 2018 update: AASLD-IDSA recommendations for testing, managing, and treating hepatitis $C$ virus infection. Clin Infect Dis. 2018;67(10):1477-92.

21. Buggisch P, Wursthorn K, Stoehr A, Atanasov PK, Supiot R, Lee J, et al. Realworld effectiveness and safety of sofosbuvir/velpatasvir and ledipasvir/ sofosbuvir hepatitis $C$ treatment in a single centre in Germany. PLoS ONE. 2019;14(4):70214795.

22. D’Ambrosio R, Pasulo L, Puoti M, Vinci M, Schiavini M, Lazzaroni S, et al. Real-world effectiveness and safety of glecaprevir/pibrentasvir in 723 patients with chronic hepatitis C. J Hepatol. 2019:70(3):379-87.
23. Kwo P, Gane EJ, Peng C-Y, Pearlman B, Vierling JM, Serfaty L, et al. Effectiveness of elbasvir and grazoprevir combination, with or without ribavirin, for treatment-experienced patients with chronic hepatitis $C$ infection. Gastroenterology. 2017;152(1):164-75

24. Rezaee-Zavareh MS, Hesamizadeh K, Behnava B, Alavian SM, GholamiFesharaki M, Sharafi H. Combination of ledipasvir and sofosbuvir for treatment of hepatitis $C$ virus genotype 1 infection: systematic review and meta-analysis. Ann Hepatol. 2017;16(2):188-97.

25. Zeng Q-L, Xu G-H, Zhang J-Y, Li W, Zhang D-W, Li Z-Q, et al. Generic ledipasvir-sofosbuvir for patients with chronic hepatitis C: a real-life observational study. J Hepatol. 2017;66(6):1123-9.

26. Merat S, Sharifi AH, Haj-Sheykholeslami A, Poustchi H, Fattahi B, NateghiBaygi A, et al. The efficacy of 12 weeks of sofosbuvir, daclatasvir, and ribavirin in treating hepatitis $C$ patients with cirrhosis, genotypes 1 and 3 . Hepat Mon. 2017;17(1):1.

27. Sharafi H, Nikbin M, Alavian SH, Behnava B, Alavian SM. Efficacy and Safety of generic sofosbuvir/ledipasvir fixed-dose combination in Iranian patients with chronic hepatitis C virus infection. Hepat Mon. 2017. https://doi.org/10.5812/hepatmon.12216.

28. Sharafi H, Alavian SH, Behnava B, Rezaee-Zavareh MS, Nikbin M, Alavian SM. Real-life efficacy of generic sofosbuvir/ledipasvir for treatment of Iranian patients with chronic hepatitis C: a cohort study. Casp J Intern Med. 2020;11(1):41.

29. Fransen L, D'hondt P, Bielen R, Van den Ende N, Robaeys G, Peerlinck $K$, et al. Elimination of hepatitis $C$ virus infection in patients with haemophilia in Belgium: a single-centre experience. Haemophilia. 2019;25(6):1028-34.

30. Guedes TP, Garrido M, Morais S, Pedroto I. High rate of SVR with DAA in haemophiliacs with HCV infection: three decades of follow-up of a Portuguese single-centre cohort. Liver Intl: Off J Int Assoc Study Liver. 2020:40:1783-4.

31. Nagao A, Hanabusa H. Brief report: the impact of ledipasvir/sofosbuvir on HIV-positive and HIV-negative Japanese hemophilia patients with 1, 4, and mixed-genotype HCV. JAIDS J Acquir Immune Defic Syndr. 2017;74(4):418-22.

32. Stedman C, Hyland R, Ding X, Pang P, McHutchison J, Gane E. Once daily ledipasvir/sofosbuvir fixed-dose combination with ribavirin in patients with inherited bleeding disorders and hepatitis C genotype 1 infection. Haemophilia. 2016;22(2):214-7.

33. Uemura H, Tsukada K, Mizushima D, Aoki T, Watanabe K, Kinai E, et al. Interferon-free therapy with direct acting antivirals for HCV/HIV-1 COinfected Japanese patients with inherited bleeding disorders. PLOS ONE. 2017;12(10):e0186255.

34. Xiao H, Chen J, Wang J, Li J, Yang F, Lu H. Antiviral therapy for $\mathrm{HCV}$ in hemophilia A patients with HIV-1 co-infection. Medicine. 2019;98(30):e16524.

35. Kowdley KV, Nelson DR, Lalezari JP, Box T, Gitlin N, Poleynard G, et al. On-treatment HCV RNA as a predictor of sustained virological response in HCV genotype 3-infected patients treated with daclatasvir and sofosbuvir. Liver Int Off J Int Assoc Study Liver. 2016;36(11):1611-8.

36. Karimi-Sari H, Rezaee-Zavareh MS. COVID-19 and viral hepatitis elimination programs: Are we stepping backward? Liver Int. 2020;40(8):2042.

37. Gregory C, Rino G, Richard G, Ghazinyan H, Dokmeci K, Tatsuo K, et al. Clinical practice guidance for hepatology and liver transplant providers during the COVID-19 pandemic: APASL expert panel consensus recommendations. Hepatol Int. 2020;14(4):415-28.

\section{Publisher's Note}

Springer Nature remains neutral with regard to jurisdictional claims in published maps and institutional affiliations. 